Original article

\title{
Spatial clustering of diabetes among reproductive age women and its spatial determinants at the district level in southern India
}

\author{
Rajeshwari A. Biradar ${ }^{\mathrm{a}, *}$, Dharmendra P. Singh ${ }^{\mathrm{b}}$ \\ ${ }^{\text {a }}$ School of Development Studies, Tata Institute of Social Sciences, Mumbai, India \\ ${ }^{\mathrm{b}}$ School of Research Methodology, Tata Institute of Social Sciences, Mumbai, India
}

\section{A R T I C L E I N F O}

\section{Keywords:}

District-level cluster

High and very high blood glucose level

Geographic cluster

Spatial analysis

Southern India

\begin{abstract}
A B S T R A C T
Background: Few recent studies have demonstrated that in India diabetes prevalence varies geographically. Differences in individual-level factors and socioeconomic status are common explanations for this variation. However, we have not come across any study on diabetes spatial clusters at the district-level among reproductive-age women in southern India. Therefore, the study was carried out to understand the spatial clustering of diabetes prevalence among reproductive-age women and its spatial determinants in southern India. Methods: National Family Health Survey (2015-16) data was used to estimate High Blood Glucose (HBG) and Very High Blood Glucose (VHBG) prevalence for women aged 15-49 years in 99 districts of southern India. We adopted advanced spatial statistical analysis such as Moran's Index and spatial regression techniques to address the study objectives.

Results: Remarkable variations were found in HBG and VHBG prevalence among 99 districts in southern India. Spatial association of HBG was found in 4 districts, and VHBG was found in 7 districts, which were hotspots. The value of the bivariate Moran's I statistics confirmed the spatial dependence between HBG and VHBG with a set of independent variables. District-level prevalence of HBG and VHBG have shown significant spatial clustering across southern Indian districts. The adjusted coefficients from the spatial error model confirmed that districtlevel proportion of tobacco use, overweight, obese, and general caste had significant associations with HBG and VHBG prevalence.

Conclusion: The study suggests that there is need for targeted intervention programs to address diabetes among reproductive-age women in high priority districts in southern India.
\end{abstract}

\section{Introduction}

Diabetes is part of a larger worldwide epidemic of non-communicable diseases. It has become a key public health challenge universally. Analysis of recent statistical data reveals that diabetes has several new epidemiological features. First, diabetes keeps growing steadily in highincome countries, such as the United States and Japan. ${ }^{1}$ Estimated that diabetes will continue to grow in the next twenty years, and more than 7 out of 10 patients will be from developing countries. ${ }^{1}$ Moreover, diabetes rates have been growing at an alarming rate in low-and middle-income countries. ${ }^{2}$ Even today, seven out of the top ten nations with the highest number of diabetes patients are from low or middleincome countries, including India. ${ }^{3}$ The prevalence of diabetes is significantly high particularly in the southern states of India as compared to northern India. ${ }^{4}$

A study based on the 11 Indian cities, shown that the age-adjusted prevalence of diabetes is higher among women than men. ${ }^{5}$ A study has shown Fasting Blood Glucose concentration (FBG), and Postprandial Blood Glucose (PPBG) were slightly higher among women in comparison to men. ${ }^{6}$ As compared to men, women have $50 \%$ of the higher relative risk for fatal coronary heart disease, which was found to be associated with diabetes. ${ }^{7}$ According to the Indian Women's Health Study, the prevalence of diabetes was $2.2 \%$ in rural and $9.3 \%$ in urban among middle-aged women. ${ }^{8}$

On the other hand, due to exposure of body fat and the increased lipid profile have shown a higher risk of diabetes prevalence among women in the developed and developing countries. In South Asians, diabetes among women was the second-highest cause for mortality. ${ }^{9}$ In 2008 around 9\% of the South East Asian women had diabetes, and 10\% were of women aged 25 years. Globally, diabetes is the ninth leading explanation of death in women, which accounts for around 2.1 million women deaths and 1.8 million deaths in men. ${ }^{2}$ The life expectancy

\footnotetext{
* Corresponding author. Tata Institute of Social Sciences, V.N. Purav Marg, Deonar, Mumbai, 400088, India.

E-mail addresses: rajeshwari.biradar2016@tiss.edu (R.A. Biradar), dpsingh@tiss.edu (D.P. Singh).
} 


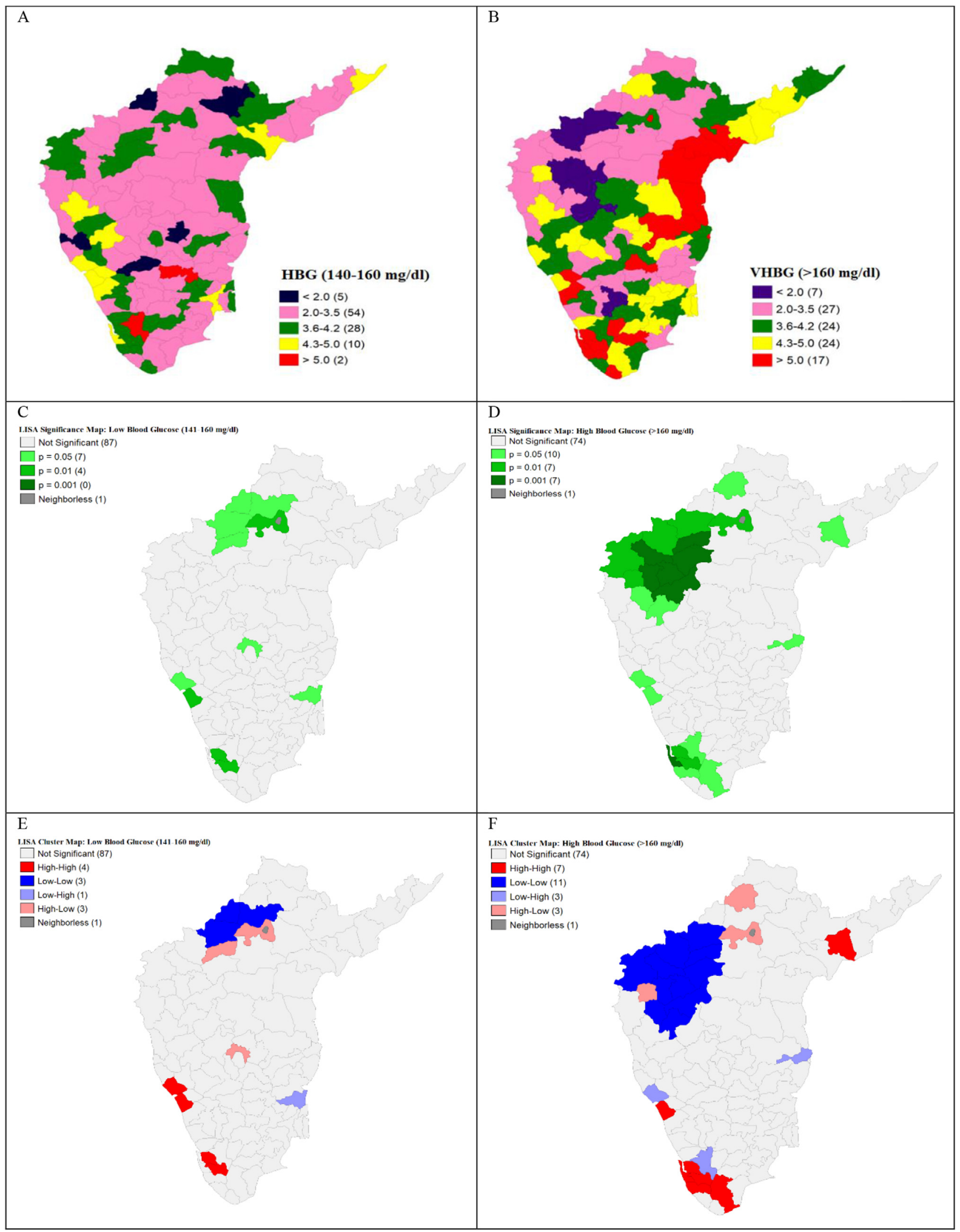

Fig. 1. Prevalence and Univariate LISA (Cluster and Significance) maps depicting spatial clustering and spatial outliers of high and very high blood glucose prevalence among 99 districts in southern India, 2015-16. A. Prevalence map of high blood glucose prevalence among 99 districts in southern India, 2015-16. B. Prevalence map of very high blood glucose prevalence among 99 districts in southern India. C. Univariate LISA Significance map of high blood glucose prevalence among 99 districts in southern India, 2015-16. D. Univariate LISA Significance map of very high blood glucose prevalence among 99 districts in southern India, 2015-16. E. Univariate LISA cluster map of high blood glucose prevalence among 99 districts in southern India, 2015-16. D. Univariate LISA cluster map of very high blood glucose prevalence among 99 districts in southern India, 2015-16. 
declines by 8.2 years among diabetic women and by 7.5 years among diabetic men as compared to who don't have the disease. Risk of heart disease grows six times in diabetic women compared to the non-diabetic woman. The significant risk factors contributing to diabetes are genetic biochemical and environmental factors. ${ }^{10-12}$ All of them, together or independently, are responsible for the development and advancement of diabetes disease - independent predictors of type 2 diabetes mellitus are Lipid abnormalities characterized by a rise in the Total Cholesterol, Triglycerides, LDL and shrinkage in the HDL concentrations. ${ }^{13}$

Overweight, obesity and physical inactivity along with lifestyle and diet also will contribute to the disease. ${ }^{14,15}$ With economic development and globalization, dietary habits have changed in India. The more intakes of saturated fats, energy-dense foods and fast foods are responsible for the major cause of concern for diabetes among women. South Asian Indians, due to their genotype, are more prone to diabetes, especially among Indians. ${ }^{16.17}$ A subtle variation in the gene sequence is associated with an increased risk of developing diabetes and its related complications. $^{18}$

A recent study has shown that women have better awareness about diabetes but not shown a significant change of behaviour to prevent diabetes disease. ${ }^{19}$ Additionally, according to NFHS-IV report, the South Indian states are not homogeneous in the prevalence of diabetes. For instance, the biometric test report of NFHS-IV indicates the prevalence of diabetes varies ( $>160 \mathrm{mg} / \mathrm{dl} /$ Very high) from 4.9 for Andhra Pradesh, 4.8 for Kerala, 3.2 for Karnataka, 3.9 for both Tamil Nadu and Telangana among women of 15-49 years compared to the national prevalence of $2.8 .^{20}$ In spite of this, we have not come across any systematic epidemiological study undertaken despite a higher prevalence of 'very high' diabetes using a national representative sample in the southern states of India. In order to contribute towards this research gap, the purpose of the study is to understand the spatial clustering of diabetes prevalence at the district level among reproductive-age women and its spatial determinants in southern Indian states.

\section{Data and methods}

The fourth round of National Family Health Survey (NFHS-IV) has been utilized to address above mentioned research gap. NFHS IV was conducted in 2015-16. International Institute for Population Sciences conducts NFHS, under the sponsorship of the Ministry of Health and Family Welfare (MoHFW), Government of India (GOI). NFHS-IV provides information on population, health and nutrition for India and all states/union territories and districts. According to NFHS-IV study design, across the country, 28,586 Primary Sampling Units (PSUs) were selected, out of this 28,522 clusters' fieldwork was completed, with a response rate of $98 \%$, a total of 601,509 households were successfully interviewed. Total 723,875 eligible women age 15-49 were identified for an interview among interviewed households. With a $97 \%$ response rate, 699,686 women participated in the survey. However, the present study has included the sample of 84,139 women aged 15-49 years from 99 districts of southern India (Andhra Pradesh, Karnataka, Kerala, Tamil Nadu and Telangana).

We used random blood glucose information, which was measured using a finger-stick blood specimen for eligible women age 15-49 using the FreeStyle Optium H Glucometer with glucose test strips. According to NFHS-IV report, the individual is classified as 'high' and 'very high' blood glucose if he/she has a random blood glucose level of $140-160 \mathrm{mg} / \mathrm{dl}$ and $\geq 160 \mathrm{mg} / \mathrm{dl}$. We considered the same definition for this study. ${ }^{20}$ Current advances in spatial analytical methods such as exploratory spatial data analysis included in GeoDa software and provide the capability to reveal spatial clusters. These methods were applied for the study of obesity, cancer, physical activity and sexually transmitted diseases. ${ }^{21,22}$ For the first time for southern India, we employed geospatial techniques like Moran's-I, univariate LISA, bivariate LISA and spatial error regression to address the research problem.
District wise shapefile of southern India have been used to show the prevalence of High Blood Glucose (HBG) and Very High Blood Glucose (VHBG) using GeoDa 1.14 software.

\section{Results}

\subsection{Diabetes prevalence}

The results are based on the aggregated district-level data. We have generated a series of maps for presenting the spatial clustering of the HBG and VHBG prevalence in 99 districts of Andhra Pradesh, Karnataka, Kerala, Tamil Nadu and Telangana states. Fig. 1A and Fig. 1B depict the districts wise HBG and VHBG prevalence among 99 districts of southern Indian states for women aged 15-49. The red colour stands districts with more than 5\% prevalence of HBG and VHBG. Among 99 districts two (Idukki in Kerala and Salem in Tamil Nadu) and seventeen (Krishna, Guntur, Prakasam, Sri Potti Sriramulu Nellore, Chittoor in Andhra Pradesh; Hyderabad in Telangana; Chennai, Dharmapuri, The Nilgiris, Virudhunagar, Theni in Tamil Nadu; Malappuram, Alappuzha, Kottayam, Pathanamthitta, Kollam, Kanniyakumari in Kerala) districts have shown more than 5\% HBG and VHBG prevalence respectively. On the other hand, high VHBG districts spread towards the coastal area of Andhra Pradesh and Tamil Nadu (red colour).

\subsection{Results of univariate local Moran's I}

Spatial analysis through local Moran's I values informs about the geographical autocorrelation for HBG and VHBG prevalence among the districts. At the district level, as per Moran's I value $6.4 \%$, and $38.2 \%$ of the districts were positively auto-correlated with the prevalence of HBG and VHBG among 99 districts. The Moran's Index's Local Indication of Special Association (LISA) map shows that seven districts on HBG prevalence (Fig. 1C) and ten districts on VHBG prevalence (Fig. 1D) were associated with a 95\% confidence interval. Similarly, HBG and VHBG prevalence was associated with a $99 \%$ confidence interval in four and seven districts. Similarly, seven districts had the highest neighbourhood association with $99.9 \%$ confidence interval in the case of VHBG. Though eighty-seven districts and seventy-four districts in southern India had no significant neighbourhood association for HBG and VHBG prevalence.

The hotspots (high to high) in red colour indicate that districts with a higher prevalence of HBG and VHBG were surrounded by neighbouring districts with greater levels of HBG and VHBG levels. Coldspots (low to low), given in blue colour, are the districts with lower levels of HBG and VHBG prevalence and also have similar neighbourhoods. Fig. 1E specifies that the spatial association of HBG prevalence was observed in four districts (Kozhikode, Kannur, Kottayam and Pathanamthitta in Kerala) 'high to high', which are 'hotspots' and three districts have shown 'low to low 'clusters for HBG prevalence, which are 'coldspots'. On the other hand, Fig. $1 \mathrm{~F}$ indicates seven districts (Kannur, Alappuzha, Kottayam, Pathanamthitta, Kollam, in Kerala; Tirunelveli in Tamil Nadu; West Godavari in Andhra Pradesh) have clustered for VHBG 'high to high', and eleven districts had 'low to low' VHBG prevalence.

\subsection{Results of bivariate local Moran's I}

Bivariate LISA estimates of spatial autocorrelation on women presented in Table 1 demonstrate compelling evidence of spatial autocorrelation between HBG and VHBG prevalence with most of the exposure variables considered in this study. Of the different exposure variables, older age group, secondary and higher education, rich wealth Index, other religions (Christian, Sikh, Buddhist/Neo-Buddhist, Jain, Jewish, Parsi/Zoroastrian, No religion, others), general caste, other occupations (Other occupations- Professional, Clerical, sales and other 
Table 1

Bivariate Moran's I spatial association between blood glucose level and their predictors among women in southern India, 2015-16.

\begin{tabular}{|c|c|c|}
\hline \multirow[t]{2}{*}{ Background Characteristics } & \multicolumn{2}{|l|}{ Women } \\
\hline & $141-160 \mathrm{mg} / \mathrm{dl}$ & $>160 \mathrm{mg} / \mathrm{dl}$ \\
\hline \multicolumn{3}{|l|}{ Age } \\
\hline $15-29$ & $-0.28(0.001)$ & $-0.45(0.001)$ \\
\hline $30-44$ & $0.21(0.001)$ & $0.28(0.001)$ \\
\hline $45-49$ & $0.20(0.001)$ & $0.39(0.001)$ \\
\hline \multicolumn{3}{|l|}{ Education } \\
\hline No Education & $-0.26(0.001)$ & $-0.32(0.001)$ \\
\hline Primary & $-0.07(0.076)$ & $-0.13(0.004)$ \\
\hline Secondary & $0.23(0.001)$ & $0.22(0.001)$ \\
\hline Higher & $0.19(0.001)$ & $0.33(0.001)$ \\
\hline \multicolumn{3}{|l|}{ Wealth Index } \\
\hline Poor & $-0.15(0.005)$ & $-0.36(0.001)$ \\
\hline Middle & $-0.13(0.013)$ & $-0.19(0.001)$ \\
\hline Rich & $0.16(0.003)$ & $0.34(0.001)$ \\
\hline \multicolumn{3}{|l|}{ Place of Residence } \\
\hline Rural & $0.01(0.396)$ & $-0.03(0.249)$ \\
\hline Urban & $-0.01(0.396)$ & $0.03(0.249)$ \\
\hline \multicolumn{3}{|l|}{ Religion } \\
\hline Hindu & $-0.18(0.002)$ & $-0.18(0.001)$ \\
\hline Muslim & $0.08(0.047)$ & $-0.04(0.185)$ \\
\hline Others & $0.18(0.001)$ & $0.32(0.001)$ \\
\hline \multicolumn{3}{|l|}{ Caste } \\
\hline $\mathrm{SC} / \mathrm{ST}$ & $-0.17(0.002)$ & $-0.24(0.001)$ \\
\hline $\mathrm{OBC}$ & $0.03(0.236)$ & $-0.04(0.227)$ \\
\hline General & $0.12(0.007)$ & $0.25(0.001)$ \\
\hline \multicolumn{3}{|l|}{ Marital Status } \\
\hline Never Married & $0.12(0.006)$ & $0.02(0.360)$ \\
\hline Currently Married & $-0.03(0.271)$ & $0.12(0.009)$ \\
\hline Others & $-0.19(0.001)$ & $-0.22(0.001)$ \\
\hline \multicolumn{3}{|l|}{ Occupation } \\
\hline No occupation & $0.11(0.012)$ & $0.07(0.085)$ \\
\hline Agriculture & $-0.16(0.001)$ & $-0.19(0.001)$ \\
\hline Others & $0.08(0.045)$ & $0.21(0.001)$ \\
\hline \multicolumn{3}{|l|}{ Body Mass Index } \\
\hline Underweight & $-0.20(0.001)$ & $-0.31(0.001)$ \\
\hline Normal & $0.07(0.072)$ & $-0.20(0.001)$ \\
\hline Overweight & $0.17(0.003)$ & $0.42(0.001)$ \\
\hline Obese & $-0.01(0.467)$ & $0.30(0.001)$ \\
\hline \multicolumn{3}{|l|}{ Tobacco Consumption } \\
\hline No & $0.11(0.01)$ & $0.24(0.001)$ \\
\hline Yes & $-0.11(0.01)$ & $-0.24(0.001)$ \\
\hline \multicolumn{3}{|l|}{ Non-Veg. weekly } \\
\hline No & $-0.02(0.307)$ & $-0.15(0.002)$ \\
\hline Yes & $0.02(0.307)$ & $0.15(0.002)$ \\
\hline \multicolumn{3}{|l|}{ Non-Veg. Occasionally } \\
\hline No & $0.04(0.245)$ & $-0.09(0.027)$ \\
\hline Yes & $-0.04(0.245)$ & $0.09(0.027)$ \\
\hline \multicolumn{3}{|l|}{ Alcohol Consumption } \\
\hline No & $0.08(0.047)$ & $0.06(0.109)$ \\
\hline Yes & $-0.08(0.047)$ & $-0.06(0.109)$ \\
\hline
\end{tabular}

than agriculture), and overweight (Body Mass Index (BMI)) consistently shown a positive and statistically significant spatial autocorrelations with both HBG and VHBG prevalence. However, obese and weekly nonvegetarian food practises also shown positive and statistically significant spatial autocorrelations with VHBG prevalence.

In the case of high blood glucose prevalence, women who are OBC caste, don't eat non-vegetarian weekly and obese shown an insignificant spatial autocorrelation. Similarly, in the case of HBG prevalence, women who are Muslim, no occupation and normal BMI have shown very low (insignificant) and positive autocorrelations. In the case of HBG and VHBG prevalence, women who are aged 15-29, have no education, belongs to poor and middle households, Hindu religion, SC/ ST caste, marital status as others (Married gauna not performed, Widowed, Divorced, Separated and Deserted), working in agricultural occupation, and having underweight BMI and tobacco use shown negative but significant autocorrelations (Table 1).

\subsection{Results of Ordinary Least Square and spatial regression model}

Results from Ordinary Least Square (OLS) and spatial regression (SAR) models describing the effect of the predictors on the outcomes, after adjusting for the spatial effect, are presented in Table 2. Based on the model diagnostics and comparing the Akaike Information Criterion (AIC) values, the Spatial Error Model (SEM) was found to be the best-fit model for all the outcome variables used in this study. Table 2 gives the estimated results of OLS, Spatial Lag Model (SLM) and Spatial Error Model (SEM) for HBG and VHBG prevalence across the 99 districts. Though the explained variabilities of the models were not directly comparable due to the nature of the estimation procedure, the introduction of spatial models could better predict the variability of HBG and VHBG prevalence across districts as evident through the improved pseudo-R-square and AIC values of the models. In the case of women who consume tobacco and overweight were consistently associated with HBG prevalence throughout the models. Similarly, women who consume tobacco, overweight, obese, and general caste were consistently associated with very high blood glucose prevalence throughout the models. Among the set of predictors, women who are overweight shown the strongest association with HBG and VHBG prevalence and a $10.0 \%$ point increase in the proportion of overweight, was significantly associated with 1.1 and $1.5 \%$ increase in HBG and VHBG prevalence (SEM model). Similarly, with an estimated $10.0 \%$ point increase in the proportion of tobacco consumption was significantly associated with 1.0 and $0.9 \%$ point increase in the HBG and VHBG prevalence among women.

Table 2

OLS, spatial lag and spatial error model estimation of high and very high Blood glucose level among women, southern India, $2015-16$.

\begin{tabular}{|c|c|c|c|c|c|c|}
\hline \multirow[t]{2}{*}{ Predictors } & \multicolumn{3}{|c|}{ High Blood Glucose (141-160 mg/dl) } & \multicolumn{3}{|c|}{ Very High Blood Glucose (> 160 mg/dl) } \\
\hline & OLS & SLM & SEM & OLS & SLM & SEM \\
\hline Others Occupation & $-0.04(0.006)$ & $-0.04(0.004)$ & $-0.04(0.004)$ & $-0.01(0.963)$ & $-0.01(0.548)$ & $-0.01(0.597)$ \\
\hline Tobacco Consumption & $0.11(0.019)$ & $0.11(0.015)$ & $0.11(0.014)$ & $0.09(0.096)$ & $0.10(0.068)$ & $0.09(0.102)$ \\
\hline Overweight & $0.11(0.000)$ & $0.12(0.000)$ & $0.11(0.000)$ & $0.15(0.000)$ & $0.13(0.000)$ & $0.15(0.000)$ \\
\hline Obese & $-0.06(0.077)$ & $-0.07(0.039)$ & $-0.06(0.070)$ & $0.10(0.026)$ & $0.12(0.008)$ & $0.10(0.027)$ \\
\hline Rich & $0.01(0.162)$ & $0.01(0.157)$ & $0.01(0.143)$ & $-0.02(0.098)$ & $-0.16(0.105)$ & $-0.02(0.070)$ \\
\hline General Caste & $0.01(0.605)$ & $0.01(0.579)$ & $0.01(0.975)$ & $0.03(0.001)$ & $0.03(0.000)$ & $0.03(0.000)$ \\
\hline Higher Education & $0.01(0.975)$ & $0.01(0.932)$ & $0.01(0.973)$ & $0.03(0.130)$ & $0.03(0.136)$ & $0.04(0.095)$ \\
\hline $\mathrm{N}$ & 99 & 99 & 99 & 99 & 99 & 99 \\
\hline$\rho$ & & $-0.08(0.467)$ & & & $0.182(0.073)$ & \\
\hline$\lambda$ & & & $0.02(0.890)$ & & & $0.154(0.278)$ \\
\hline AIC & 236.5 & 238.0 & 236.5 & 280.69 & 279.51 & 279.79 \\
\hline Adjusted $\mathrm{R}^{2}$ & 0.237 & 0.280 & 0.276 & 0.510 & 0.557 & 0.546 \\
\hline
\end{tabular}

Note: Other Occupation- Professional, Clerical, sales and other than agriculture. 


\section{Discussion}

Globally, the data on a similar prevalence of diabetes are rare. International Diabetes Federation estimated 9.3\% (age-standardized by considering the global population as standard) of Indians and $8.8 \%$ of World's adults with diabetes. ${ }^{23}$ By using the subset of the national-level survey data for southern India, this study examined the seriousness of HBG and VHBG prevalence among 99 southern Indian districts. The present investigation has shown a higher prevalence of HBG in Idukki in Kerala, Salem in Tamil Nadu. Similarly, we found that the higher prevalence of VHBG in Krishna, Guntur, Prakasam, Sri Potti Sriramulu Nellore, Chittoor in Andhra Pradesh; Hyderabad in Telangana; Chennai, Dharmapuri, The Nilgiris, Virudhunagar, Theni in Tamil Nadu; Malappuram, Alappuzha, Kottayam, Pathanamthitta, Kollam, Kanniyakumari in Kerala districts. However, studies have shown total fat intake in Kerala is $30 \%$ of the energy with $70 \%$ of that (20\% of daily energy) coming from saturated fat. Substantial servings of coconut meat, milk and oil is used for preparing nearly every dishes with vegetables, fish and even meat and bread (Palappam, Vattayappam). ${ }^{24,25}$

However, a key contribution of the study is that the identification of hotspots (that is, regions with high HBG and high VHBG) and coldspots (regions with low HBG and low VHBG) within southern India. There is a lack of understating how the epidemic is spread in southern India among researchers and policymakers. This study clearly brings out spatial contours where the HBG and VHBG prevalence is clustered. The findings depict geographic regions that need immediate and careful attention of the policymakers, where the highest prevalence of HBG and VHBG exist. The study found district level HBG and VHBG prevalence in southern India was spatially associated and that significant of HBG and VHBG clusters ('high to high') shown in four (Kozhikode, Kannur, Kottayam and Pathanamthitta in Kerala) and seven (Kannur, Alappuzha, Kottayam, Pathanamthitta, Kollam, in Kerala; Tirunelveli in Tamil Nadu; West Godavari in Andhra Pradesh) districts. Several studies have shown in the United States high diabetes prevalence clusters at one belt. ${ }^{26,27}$

Similarly, our study found districts in which HBG and VHBG prevalence was higher, had similar neighbouring districts were concentrated in Kerala, to a large extent corresponding with the location of the VHBG prevalence in Kerala and Tamil Nadu. Additionally, districts with where VHBG prevalence was lower, and similar neighbouring districts with low VHBG prevalence were concentrated in the northern Karnataka. The state and district level geographical spatial variations in the prevalence of diabetes in India are also documented. The study observed the medium to high-level clustering of HBG and VHBG in the southern Indian districts. Two fifth and three-fifth of the districts have observed a higher prevalence of HBG and VHBG than the national average. Generally, districts in coastal regions of the country reported significantly higher VHBG prevalence. On the other hand, three districts were spatially associated low-high diabetes and these districts observed in the coastal belt. A study by Ghosh et al. (2019) found that diabetes prevalence was positively related with per capita calorie consumption in India, especially the positive association was per capita calorie intake from sugar and the production of sugar crops. ${ }^{28}$

The finding of this study suggests that rich wealth index, other occupations (other occupation- Professional, Clerical, sales and other than agriculture), overweight BMI had a positive impact on the HBG and VHBG prevalence. The previous study found that concurrent reduction in physical activities and the rapid increase in the consumption of sugar and fats in India has resulted into significate increases in the prevalence of diabetes. ${ }^{29}$ On the other hand, the intake of staple foods (maize, rice, wheat, pulses and roots) significantly decreases the risk of diabetes. ${ }^{30}$

The study also revealed that secondary and higher education had a positive influence on the HBG and VHBG prevalence in southern Indian states. A study by Deepa et al. (2014) found that a better awareness of diabetes among literates as compared to illiterates in India. ${ }^{31}$ On the other hand, Olasson et al. (2011) study shown diabetes prevalence was higher among higher educated. ${ }^{32}$ Yet to date, there is no national awareness survey on diabetes, but a study in Chennai found that awareness of diabetes prevention is deprived, especially among women and people with little education. ${ }^{33}$ Another key finding was that obesity and weekly eating of non-vegetarian food have a positive impact on the VHBG prevalence. A study by Gothankar (2011) found that obesity and waist circumference was associated with hypertension and diabetes. ${ }^{34}$ However, females were more obese than men ${ }^{35}$ and obesity most found among the affluent class, higher occupation level and higher education status. $^{36}$

\section{Conclusions}

The study has highlighted the significant variation in the distribution of HBG and VHBG prevalence among reproductive-age women across districts in southern Indian states. Many neighbourhood districts were correlated with HBG and VHBG prevalence. The hotspots of HBG and VHBG prevalence's were observed in neighbourhood districts of Kerala, and Tamil Nadu states. The study helps Policymakers to develop specific regional strategies to address the seriousness of diabetes prevalence among reproductive-age women. Also, the study brought insights to the programmers who lack knowledge of spatial clustering of diabetes in southern India, and findings help micro-planning at the district level to address modifiable essential risk factors for diabetes.

\section{Funding}

This work did not receive any funding.

\section{Availability of data and materials}

The study has used the fourth round of the National Family Health Survey (NFHS-4) data, which is publicly available on the Demography and Health Servery (DHS) website (https://dhsprogram.com/).

\section{Declaration of competing interest}

The authors declare that they have no competing interests.

\section{References}

1. Wild S, Roglic G, Green A, Sicree R, King H. Global prevalence of diabetes: estimates for the year 2000 and projections for 2030. Diabetes Care. 2004 May 1;27(5):1047-1053.

2. World Health Origination. Diabetes. https://www.who.int/news-room/fact-sheets/ detail/diabetes, Accessed date: 20 June 2019.

3. Diamond J. Diabetes in India. Nature. 2011 Jan;469(7331):478.

4. Ghosh K, Dhillon P, Agrawal G. Prevalence and detecting spatial clustering of diabetes at the district level in India. J Public Health. 2019 1-1.

5. Gupta A, Gupta R, Sharma KK, et al. Prevalence of diabetes and cardiovascular risk factors in middle-class urban participants in India. BMJ Open Diabetes Res Care. 2014 Dec 1;2(1):e000048.

6. Cheekurthy AJ, Rambabu C, Kumar A. Prevalence of type 2 diabetes mellitus among women and the associated risk factors. J. Nurs. Health Sci. 2016.

7. Huxley R, Barzi F, Woodward M. Excess risk of fatal coronary heart disease associated with diabetes in men and women: meta-analysis of 37 prospective cohort studies. Bmj. 2006 Jan 12;332(7533):73-78.

8. Pandey RM, Gupta R, Misra A, et al. Determinants of urban-rural differences in cardiovascular risk factors in middle-aged women in India: a cross-sectional study. Int J Cardiol. 2013 Feb 20;163(2):157-162.

9. Bajaj S, Jawad F, Islam N, et al. South Asian women with diabetes: psychosocial challenges and management: consensus statement. Indian J. Endocrinol. Metabol. 2013 Jul; 17(4):548.

10. Hua Y, Shen J, Song Y, Xing Y, Ye X. Interleukin-10 - 592C/A, - 819C/T and 1082A/G polymorphisms with risk of type 2 diabetes mellitus: a HuGE review and meta-analysis. PloS One. 2013 Jun 21;8(6):e66568.

11. Cheekurthy AJ, Rambabu C, Kumar A. Biochemical biomarkers-independent predictors of type 2 diabetes mellitus. J Bioanal Biomed. 2015 Mar 1;7(2):35https://pdfs. semanticscholar.org/06c7/aeef136f5e5df0164438ab d9b1 535f095a0b. pdf.

12. Hamman RF. Genetic and environmental determinants of non-insulin-dependent diabetes mellitus (NIDDM). Diabetes Metab Rev. 1992 Dec;8(4):287-338.

13. Bitzur R, Cohen H, Kamari Y, Shaish A, Harats D. Triglycerides and HDL cholesterol: stars or second leads in diabetes? Diabetes Care. 2009 Nov 1;32(suppl 2):S373-S377. 
14. Eckel RH, Kahn SE, Ferrannini E, et al. Obesity and type 2 diabetes: what can be unified and what needs to be individualized? J Clin Endocrinol Metabol. 2011 Jun 1;96(6):1654-1663.

15. Admiraal WM, van Valkengoed IG, L de Munter JS, Stronks K, Hoekstra JB, Holleman F. The association of physical inactivity with Type 2 diabetes among different ethnic groups. Diabet Med. 2011 Jun;28(6):668-672.

16. Gujral UP, Pradeepa R, Weber MB, Narayan KV, Mohan V. Type 2 diabetes in South Asians: similarities and differences with white Caucasian and other populations. Ann N Y Acad Sci. 2013 Apr;1281(1):51.

17. Mohan V. Why are Indians more prone to diabetes? J Assoc Phys India. 2004 Jun $1 ; 52: 468-474$.

18. Cheekurthy AJ, Rambabu C, Kumar A. Gene as a risk factor for type 2 diabetes mellitus and its related complications. Biomed Res Clin Prac. 2016;1:14-17.

19. Nasline $S$. Women's diabetes in numbers: why female population in India ignores the risks. Accessed on 30-12-19 Link://economictimes.indiatimes.com/articleshow/ 63590014.cms?utm_source $=$ content ofinterest\&utm_medium $=$ text\&utm_ campaign $=$ cppst.

20. IIPS I. National Family Health Survey (NFHS-4), 2015-16: India. Mumbai: International Institute for Population Sciences; 2017.

21. Goovaerts P. Geostatistical analysis of county-level lung cancer mortality rates in the Southeastern United States. Geogr Anal. 2010;42(1):32-52.

22. Chen DR, Wen TH. Elucidating the changing socio-spatial dynamics of neighborhood effects on adult obesity risk in Taiwan from 2001 to 2005. Health Place. 2010 Nov 1;16(6):1248-1258

23. Atlas D. International Diabetes Federation. IDF Diabetes Atlas. seventh ed. Brussels, Belgium: International Diabetes Federation; 2015.

24. Soman CR, Kutty VR, Safraj S, et al. All-cause mortality and cardiovascular mortality in Kerala State of India: results from a 5-year follow-up of 161942 rural community dwelling adults. Asia Pac J Publ Health. 2011 Nov;23(6):896-903.

25. Soman CR, Shahulhameed S, Ramankutty V, et al. PROLIFE study group. Cohort profile: the PROLIFE study in Kerala, India. Int J Epidemiol. 2009 Sep 8;40(1):10-14.

26. Barker LE, Kirtland KA, Gregg EW, Geiss LS, Thompson TJ. Geographic distribution of diagnosed diabetes in the US: a diabetes belt. Am J Prev Med. 2011 Apr 1;40(4):434-439.

27. Shrestha Sundar S, Kirtland Karen A, Thompson Theodore J, Barker L, Gregg Edward W, Geiss L. Spatial clusters of county-level diagnosed diabetes and associated risk factors in the United States. Open Diabetes J. 2012 Nov 26;5(1).

28. Ghosh K, Dhillon P, Agrawal G. Prevalence and detecting spatial clustering of diabetes at the district level in India. J Public Health. 2019 1-1.

29. Gulati S, Misra A. Sugar intake, obesity, and diabetes in India. Nutrients. 2014 Dec;6(12):5955-5974.

30. Mattei J, Malik V, Wedick NM, et al. Reducing the global burden of type 2 diabetes by improving the quality of staple foods: the Global Nutrition and Epidemiologic Transition Initiative. Glob Health. 2015 Dec;11(1):23.

31. Deepa M, Bhansali A, Anjana RM, et al. Knowledge and awareness of diabetes in urban and rural India: the Indian Council of Medical Research India diabetes study (phase I): Indian Council of Medical Research India diabetes 4. Indian J. Endocrinol. Metabol. 2014 May;18(3):379.

32. Olsson L, Ahlbom A, Grill V, Midthjell K, Carlsson S. High levels of education are associated with an increased risk of latent autoimmune diabetes in adults: results from the Nord-Trøndelag health study. Diabetes Care. 2011 Jan 1;34(1):102-107.

33. Murugesan N, Snehalatha C, Shobhana R, Roglic G, Ramachandran A. Awareness about diabetes and its complications in the general and diabetic population in a city in southern India. Diabetes Res Clin Pract. 2007 Sep 1;77(3):433-437.

34. Gothankar JS. Prevalence of obesity and its associated co-morbidities amongst adults. Natl J Community Med. 2011 Jul;2(2):221-224.

35. Nagendra K, Nandini C, Belur M. A community based study on prevalence of obesity among urban population of Shivamogga, Karnataka, India. Int J Community Med. Publ Health. 2016 Dec 21;4(1):96-99.

36. Tiwari R, Srivastava D, Gour N. A cross-sectional study to determine prevalence of obesity in high income group colonies of Gwalior city. Indian J Community Med. 2009 Jul;34(3):218 official publication of Indian Association of Preventive \& Social Medicine. 